\title{
Chemical, Magnetic and X-Ray Diffraction Studies of the Sediments from Oil Field in Argentina
}

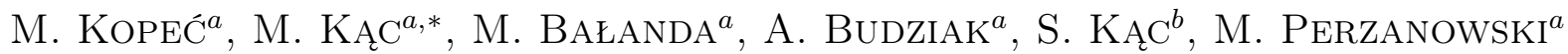 \\ AND M. GÓRA ${ }^{b}$ \\ ${ }^{a}$ The Henryk Niewodniczański Institute of Nuclear Physics, Polish Academy of Sciences, Kraków, Poland \\ ${ }^{b}$ AGH - University of Science and Technology, Kraków, Poland
}

\begin{abstract}
Chemical, magnetic, and phase composition analysis of deposits taken from sedimentation tank from oil plant in Argentina was carried out. Energy dispersive spectroscopy indicates iron as a main sediment component with the site dependent fraction ranging from $11 \%$ to $78 \%$ (weight percentage). Moreover, large fractions of sulfur (4\%-33\%), oxygen ( $8 \%-28 \%)$, calcium (1\%-14\%), and silicon (1\%-11\%) were found. The chemical analysis performed with wet chemical methods also indicated $\mathrm{Fe}$ as a main component (about 35\%), additionally a large fraction $(\approx 15 \%)$ of the sulfur and under $10 \%$ fractions of calcium $(\approx 7 \%)$, carbon $(\approx 6 \%)$, and silicon $(\approx 5 \%)$ were found in the sample. The phase composition studies performed using X-ray diffraction showed magnetite $-\mathrm{Fe}_{3} \mathrm{O}_{4}$, goethite $-\alpha-\mathrm{FeOOH}$, lepidocrocite $-\gamma-\mathrm{FeOOH}$, siderite $-\mathrm{FeCO}_{3}$, and iron-sulfur compounds (mackinawite - FeS, stoichiometric $\mathrm{FeS}$, greigite - $\mathrm{Fe}_{3} \mathrm{~S}_{4}$ ) and other compounds like aragonite $\mathrm{CaCO}_{3}$, calcite $-\mathrm{CaCO}_{3}$, anorthite $-\mathrm{CaAl}_{2} \mathrm{Si}_{2} \mathrm{O}_{8}$, quartz $-\mathrm{SiO}_{2}$ and barium sulphate $\mathrm{Ba}\left(\mathrm{SO}_{3}\right)_{0.3}\left(\mathrm{SO}_{4}\right)_{0.7}$. Studies performed by the Mössbauer spectroscopy, confirmed presence of majority of compounds identified by X-ray diffraction. Magnetic AC susceptibility measurements show that magnetite is a main component of the studied deposit. High concentration of the magnetic compounds deposited in the sedimentation tank points to the advisability to install the magnetic device designed to support water treatment processes, i.e.: flocculation, coagulation, sedimentation, and filtration. This device could simultaneously inhibit microbiological and chemical corrosion.
\end{abstract}

PACS: 82.80.Ej, 89.20.Bb, 89.30.aj

\section{Introduction}

The oil structurally trapped in a typical reservoir (a rock formation that contains hydrocarbons) can be produced either under its own pressure (a primary production process) or under applied external pressure by water injection (a secondary production process). Because of low productivity of the primary recovery process, the secondary recovery technologies are essential. In the water flooding recovery technique the oil is displaced by water from the reservoirs and moved via porous rock formation towards the wells. The obtained water-in-oil emulsion contains dispersed fine solids which penetrate the oil during production process. The production stream is passed through separation equipment to separate oil, gas, water, and suspended solids. The separated oil is recovered and the separated water is reinjected into the reservoir rocks as additional flooding water. The suspended solids are deposited in the sedimentation tank. Not sufficiently purified water (containing dispersed solids) can be responsible for the loss of the rock permeability caused by particles trapped in small pores [1].

Water injection stimulates the productivity of oil reservoirs, but a consequence may be an increase of microbiological and chemical corrosion. The mixture of oil and water provides favorable growth conditions for sulphate-

* corresponding author; e-mail: malgorzata.kac@ifj.edu.pl -reducing bacteria (SRB). SRB reduce sulphate to hydrogen sulfide $\left(\mathrm{H}_{2} \mathrm{~S}\right)$, which causes corrosion of iron and steel alloys in oil wells and in the oil-processing system [2]. Water flood can also inject oxygen into the oil formation, promoting oxygen corrosion (oxidation). Precipitation of corrosion products (oxides and sulfides) in the oil reservoir may also reduce the permeability of the oil formation. The water can be more effectively purified by speeding up of particle coagulation and sedimentation and/or better filtration. Such enhancement can proceed in magnetic field when the significant fraction of dispersed solids is magnetic.

Inorganic mineral compounds in injected water can be also deposited on the surfaces of production equipment resulting in a decrease in oil production. The most common of the mineral scales in oil production process are calcium carbonates and calcium, strontium and barium sulphates [3]. To control mineral scales, different chemicals interfering with crystal growth are used. Magnetic treatment of injected water can protect the system from the precipitation of hard carbonate deposits (calcite) reducing amount of introduced chemicals [4].

In this paper the authors analyzed the composition of the deposits from sedimentation tank from oil plant in Argentina. Besides the chemical and structural analysis, magnetic measurements were performed in order to estimate the concentration of magnetic phases. Enough high concentration of the magnetic components of the deposit makes useful to install the magnetic device designed 
to support water treatment processes, such as: flocculation, coagulation, sedimentation and filtration, moreover this device can inhibit microbiological and chemical corrosion [5].

\section{Experimental}

The sediments obtained from the storage tank, in the form of sedimentary rock, particles and conglomerates, were crushed in the mortar into a fine powder form. The basic chemical analysis of the sediments was performed with wet chemical methods using gravimetry and titrimetry for quantitative chemical measurements. The sample was examined in the Hitachi S-3500N scanning electron microscope (SEM) and chemically analyzed using Noran 986B-1SPS EDS (energy dispersive spectroscopy). The phase analysis of deposits was performed by X-ray diffraction (XRD) technique. The XRD measurements were carried out on the Panalytical X'Pert Pro diffractometer with $\mathrm{Cu} K_{\alpha}(\lambda=0.154056 \mathrm{~nm})$ radiation operated at $40 \mathrm{kV}$ and $30 \mathrm{~mA}$. The magnetic properties of sediments were studied by means of the 7225 Lake Shore AC susceptometer/DC magnetometer. Both real $\left(\chi^{\prime}\right)$ and imaginary $\left(\chi^{\prime \prime}\right)$ components of AC susceptibility $\chi_{\mathrm{AC}}=\chi^{\prime}-\mathrm{i} \chi^{\prime \prime}$ were registered as a function of temperature. The measurements were performed with $125 \mathrm{~Hz}$ frequency and at 5 Oe of the oscillating magnetic field. Magnetization as a function of applied magnetic field up to $56 \mathrm{kOe}$ was measured at $4.2 \mathrm{~K}$ by the extraction method using the DC option of the Lake Shore instrument. Moreover, the phase analysis and magnetic properties investigation were performed using the Mössbauer spectroscopy (MS) technique. The Mössbauer measurements were carried out in transmission geometry, at room temperature, with $100 \mathrm{mCi} \mathrm{Co}(\mathrm{Rh})$ source. The Mössbauer spectra were fitted using Voigt-based method of Rancourt and Ping [6] as a sum of Gaussian components for the hyperfine magnetic field $\left(B_{\mathrm{hf}}\right)$, isomer shift (IS) and quadrupole splitting (QS) distributions.

\section{Results and discussion}

The morphology of the sediments was observed by scanning electron microscopy (SEM). The SEM picture presented in Fig. 1 shows conglomerates (from 1 to $7 \mu \mathrm{m}$ ) and fine particles below $1 \mu \mathrm{m}$ diameter. The EDS analysis (Table I) performed in different areas of the samples indicates Fe as a main component with the site dependent fraction ranging from $11 \%$ to $78 \%$ (weight percentage). Additionally, large fractions of sulfur (4\%-33\%), oxygen $(8 \%-28 \%)$, calcium $(1 \%-14 \%)$ and silicon $(1 \%-11 \%)$ were found. The fraction of oxygen is determined with a large error because such light elements are very close to the detection limit of the EDS spectrometer. Aluminum with fraction changing from 0 to $4 \%$ (and $71 \%$ in one point) was detected. Besides above mentioned elements, barium with fraction changing from $1 \%$ to $9 \%$, and very small amounts of sodium, magnesium and potassium with fractions not higher than $4 \%$ were observed.

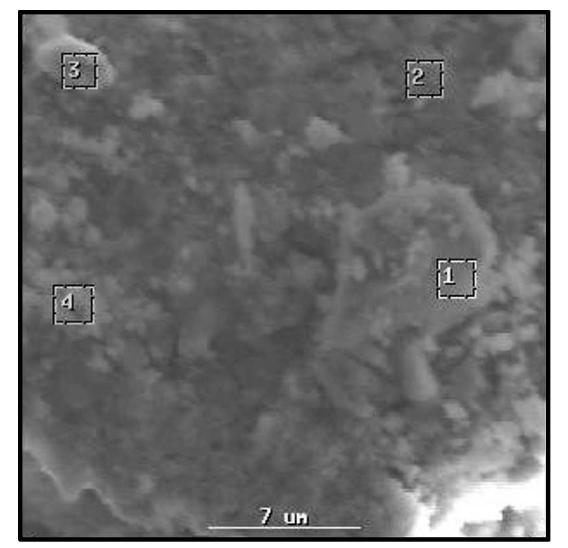

Fig. 1. SEM picture of sediments with four marked areas where EDS analysis was performed.

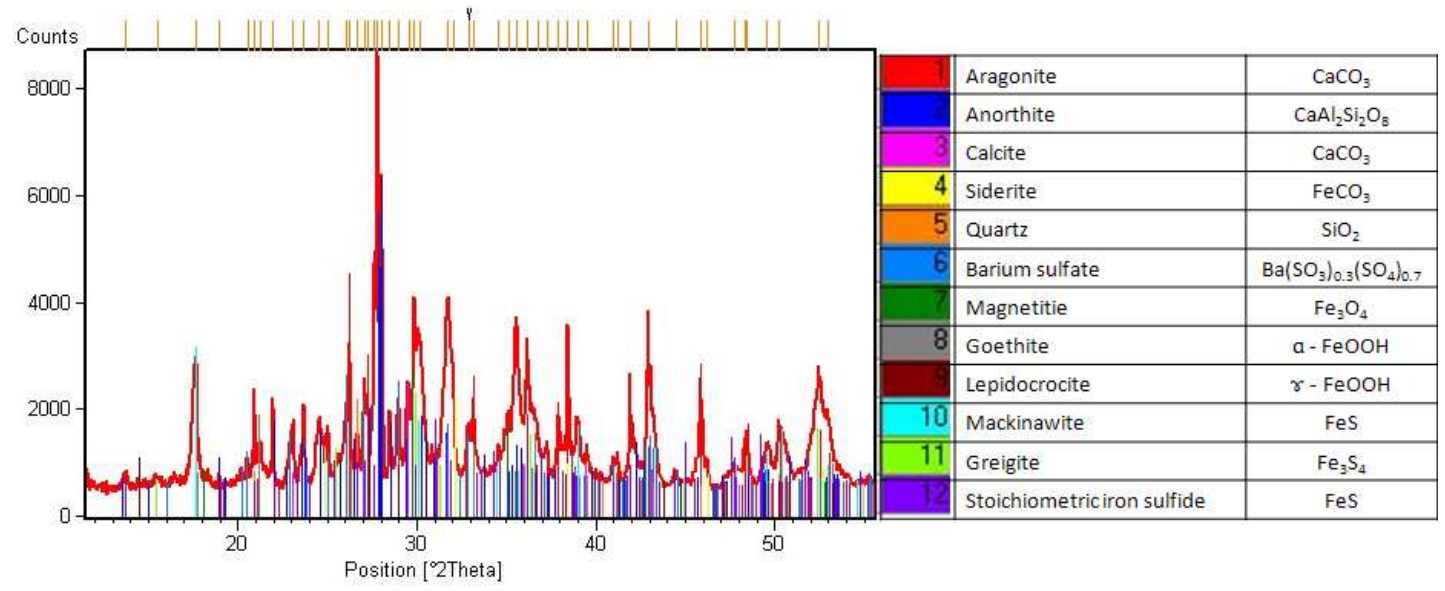

Fig. 2. XRD pattern of sediments with marked positions of peaks coming from identified phases (in the table). 
TABLE I

Chemical analysis of the sediments performed by means of EDS spectrometer in different areas of the sample.

\begin{tabular}{c|c}
\hline \hline Elements & $\begin{array}{c}\text { Composition range } \\
\text { (weight percentage) }\end{array}$ \\
\hline $\mathrm{Fe}$ & $11-78$ \\
$\mathrm{~S}$ & $4-33$ \\
$\mathrm{O}$ & $8-28$ \\
$\mathrm{Ca}$ & $1-14$ \\
$\mathrm{Si}$ & $1-11$ \\
$\mathrm{Ba}$ & $1-9$ \\
$\mathrm{Al}$ & $0-71$ \\
$\mathrm{Na}$ & $0-4$ \\
$\mathrm{Mg}$ & $0-1$ \\
$\mathrm{~K}$ & $0-1$
\end{tabular}

TABLE II

Identified elements with attributed weight composition obtained from wet chemical analysis of the sediments by means of gravimetry and titrimetry methods.

\begin{tabular}{c|c}
\hline \hline \multicolumn{2}{c}{ Chemical analysis } \\
\hline Elements & $\begin{array}{c}\text { Composition } \\
\text { (weight percentage) }\end{array}$ \\
\hline $\mathrm{Si}\left(\right.$ as $\left.\mathrm{SiO}_{2}\right)$ & $4.69(10.03)$ \\
$\mathrm{Ca}($ as $\mathrm{CaO})$ & $7.48(10.48)$ \\
$\mathrm{C}$ & 5.59 \\
$\mathrm{~S}$ & 14.98 \\
$\mathrm{Fe}^{++}($as FeO$)$ & $22.44(28.87)$ \\
$\mathrm{Fe}^{+++}\left(\right.$as $\left.\mathrm{Fe}_{2} \mathrm{O}_{3}\right)$ & $12.27(17.54)$
\end{tabular}

The chemical analysis of the sediments was also carried out with a wet chemical method. The outcomes of that analysis are presented in Table II where distinguished elements with attributed weight composition are shown. The results, as in the case of EDS analysis, also indicate $\mathrm{Fe}$ as a main component (about $35 \%$ ) of sediments appearing in the form of $\mathrm{Fe}(\mathrm{II})(\approx 22 \%)$ and $\mathrm{Fe}(\mathrm{III})$ $(\approx 12 \%)$. Moreover, a large fraction $(\approx 15 \%)$ of the sulfur and under $10 \%$ fractions of calcium $(\approx 7 \%)$, carbon $(\approx 6 \%)$ and silicon $(\approx 5 \%)$ was found in the sample.

In Fig. 2 the XRD pattern of the sediment powder is presented. The spectrum is quite complicated with many peaks which are difficult to identify due to the environmental character of our sample. As a result of rough analysis one may distinguish iron compounds (magnetite $\mathrm{Fe}_{3} \mathrm{O}_{4}$, goethite $-\alpha-\mathrm{FeOOH}$, lepidocrocite $-\gamma$ - $\mathrm{FeOOH}$, siderite - $\mathrm{FeCO}_{3}$ ), iron-sulfur compounds (mackinawite - FeS, stoichiometric $\mathrm{FeS}$, greigite - $\left.\mathrm{Fe}_{3} \mathrm{~S}_{4}\right)$ and other compounds like aragonite $-\mathrm{CaCO}_{3}$, calcite $-\mathrm{CaCO}_{3}$,

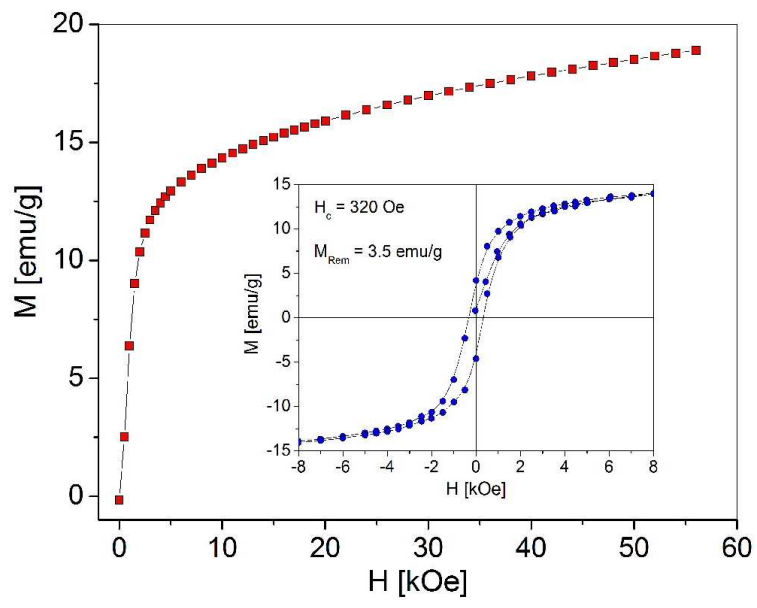

Fig. 3. Magnetization curve and the hysteresis loop measured at $4.2 \mathrm{~K}$.

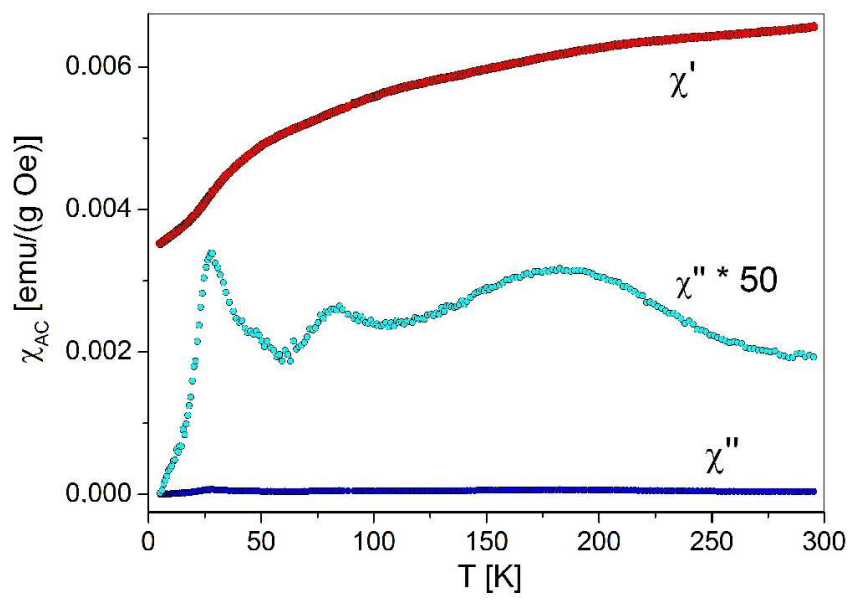

Fig. 4. Temperature dependence of the AC susceptibility $\chi_{\mathrm{AC}}=\chi^{\prime}-\mathrm{i} \chi^{\prime \prime}$, with imaginary $\left(\chi^{\prime \prime}\right)$ component shown in enlargement.

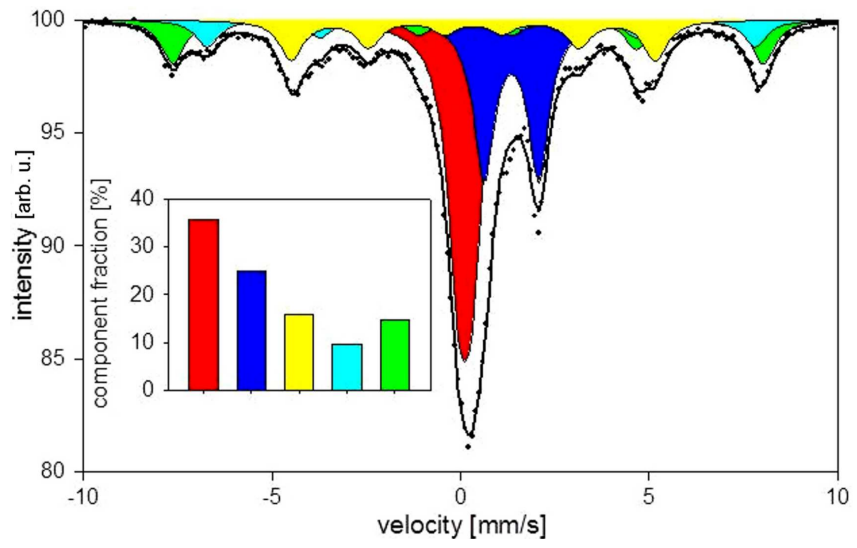

Fig. 5. Mössbauer spectrum of the sediments with the fitted subspectra. In the inset the fraction of each component is shown. 
anorthite $-\mathrm{CaAl}_{2} \mathrm{Si}_{2} \mathrm{O}_{8}$, quartz $-\mathrm{SiO}_{2}$ and barium sulphate $\mathrm{Ba}\left(\mathrm{SO}_{3}\right)_{0.3}\left(\mathrm{SO}_{4}\right)_{0.7}$.

Magnetic properties of the sediments were investigated by means of the Lake Shore instrument and the Mössbauer spectrometer. Figure 3 shows the magnetization curve and the hysteresis loop measured at $4.2 \mathrm{~K}$. In the highest field available equal to $56 \mathrm{kOe}$ magnetization does not saturate which suggests the large contribution from paramagnetic materials. However, the hysteresis loop is also observed with coercive field equal to 320 Oe and the magnetic remanence value of $3.5 \mathrm{emu} / \mathrm{g}$. Such hysteresis behavior is the evidence for the presence of magnetically ordered phases in the deposit. It is known that the ferrimagnetic magnetite (or greigite)-based minerals are the most common environmental magnets [7]. Figure 4 gives the temperature dependence of the $\mathrm{AC}$ suscepti- bility $\chi_{\mathrm{AC}}=\chi^{\prime}-\mathrm{i} \chi^{\prime \prime}$, with imaginary component $\chi^{\prime \prime}$ shown in enlargement. The real component of susceptibility increases with the temperature, while the imaginary component reveals narrow peak at $25 \mathrm{~K}$ and two broad maxima at $80 \mathrm{~K}$ and $180 \mathrm{~K}$. Continuous rise of real component can indicate presence of ferromagnetic particles in our sediments. The behavior of imaginary component, especially first part of the curve is very similar to magnetite imaginary component, where also narrow maximum at about $30 \mathrm{~K}$ is observed [8]. It can suggest a significant fraction of magnetite in studied deposits. No clear features characteristic for magnetite Verwey transition $(\approx 120 \mathrm{~K})$ may be due to high imperfection level such as deviation from stoichiometry, polycrystalline structure, impurities [9] and does not exclude magnetite as a main magnetic component of our sample.

TABLE III

Hyperfine parameters and fractions of the fitted components of the Mössbauer spectrum measured for the sediments.

\begin{tabular}{c|c|c|c|c|c}
\hline \hline Component & $\begin{array}{c}\text { Relative } \\
\text { intensity }\end{array}$ & Subspectrum & $B_{\mathrm{hf}}[\mathrm{T}]$ & $\begin{array}{c}\mathrm{QS} \\
{[\mathrm{mm} / \mathrm{s}]}\end{array}$ & $\begin{array}{c}\mathrm{IS} \\
{[\mathrm{mm} / \mathrm{s}]}\end{array}$ \\
\hline 1 & 35 & singlet & 0 & 0.17 & 0.12 \\
2 & 25 & doublet & 0 & 0.72 & 1.35 \\
3 & 16 & sextet & 48.4 & 0.03 & 0.17 \\
4 & 10 & sextet & 45.0 & 0.03 & 0.52 \\
5 & 14 & sextet & 29.9 & -0.01 & 0.34
\end{tabular}

The sample was also studied using the Mössbauer spectroscopy. In Fig. 5 the Mössbauer spectrum with subspectra and the component fraction in the inset are shown. The spectrum was fitted by 5 components appearing with relevant fractions and characterized by hyperfine parameters: hyperfine magnetic field $\left(B_{\mathrm{hf}}\right)$, quadrupole splitting (QS) and isomer shift (IS) presented in Table III. Three components fitted by sextets indicate the magnetic surrounding of Fe nucleus, additionally one component fitted by doublet and one component fitted by singlet were distinguished. The magnetic components with the largest values of $B_{\mathrm{hf}}$ equal to $48.4 \mathrm{~T}$ and $45.0 \mathrm{~T}$ suggest the presence of ferrimagnetic magnetite $\mathrm{Fe}_{3} \mathrm{O}_{4}$ compound $[10,11]$. The component with larger $B_{\mathrm{hf}}$ and smaller IS corresponds to trivalent $\mathrm{Fe}$ ions located at the tetrahedral A sites, while the other one is interpreted as average signal of $\mathrm{Fe}^{3+}$ and $\mathrm{Fe}^{2+}$ ions at the octahedral $\mathrm{B}$ sites of magnetite.

The intensity ratio of both components deviates considerably from expected 1:2 probably due to high impurity and/or vacancy concentrations. The second magnetic component with $B_{\mathrm{hf}}$ equal to $29.9 \mathrm{~T}$ could be related to iron sulfide such as antiferromagnetic, stoichiometric $\mathrm{FeS}$ or ferrimagnetic greigite $\mathrm{Fe}_{3} \mathrm{~S}_{4}$. All these compounds are characterized by sextets in the Mössbauer spectrum and assume about $30 \mathrm{~T}$ value of hyperfine magnetic field [11-13]. Among non-magnetic components constituting majority of the spectrum $(60 \%)$ there is one double and one single line. The doublet with fraction equal to $25 \%$ can correspond to paramagnetic lepidocrocite $\gamma-\mathrm{FeOOH}$, diamagnetic pyrite $\mathrm{FeS}_{2}$ or antiferromagnetic goethite $\alpha$-FeOOH $[12,14]$. This doublet can be also related to paramagnetic siderite $\mathrm{FeCO}_{3}$ however considerably smaller value of QS can suggest significant doping level or vacancy concentration. Moreover, it can be also related to superparamagnetic particles of iron oxide or hydroxides particles smaller than $10 \mathrm{~nm}$ [14]. Single line appearing with the largest fraction in our spectrum (35\%) corresponds to Fe atoms in nonmagnetic surrounding. It may be related to superparamagnetic particles but it could be also interpreted as iron doped illite [10].

\section{Conclusions}

The analyzed deposits can be identified as rock formation minerals, common oil field scales (scales deposited on the surface oil production equipment) and corrosion 
products. Rock formation minerals like magnetite, anorthite, and silicon oxide were found. Identified calcium carbonate and barium sulphate are the most common oil field scales. Moreover, various types of corrosion products were distinguished: oxide corrosion products (magnetite, goethite, lepidocrocite); carbon dioxide corrosion products (siderite); and hydrogen sulfide (SRB) corrosion products (greigite and mackinawite). High concentration of the magnetic particles makes useful to install the magnetic device designed to support water treatment processes, such as: flocculation, coagulation, sedimentation and filtration. This device could simultaneously inhibit microbiological and chemical corrosion. Magnetic treatment of injected water can also protect the production system from the precipitation of hard carbonate deposits (calcite). Getting information on the phase composition of deposits from the sedimentation tank allows for better selection of water treatment methods to reduce serious environmental problems associated with the oil production process.

\section{References}

[1] L.L. Schramm, Emulsions, Foams and Suspensions. Fundamentals and Applications, Wiley-VCH, Weinheim 2005.

[2] R. Cord-Ruwisch, W. Kleinitz, F. Widdel, J. Petrol. Technol. 39, 97 (1987).
[3] M. Amiri, J. Moghadasi, Asian J. Sci. Res. 3, 230 (2010).

[4] A. Szkatuła, M. Bałanda, M. Kopeć, Eur. J. Appl. Phys. 18, 41 (2002).

[5] M. Kopeć, A. Szkatuła, M. Kąc, Device for Fe compound removing from water by magnetic field, $\mathrm{PL}$ Patent No. P393467.

[6] D.G. Rancourt, J.Y. Ping, Nucl. Instrum. Methods Phys. Res. B 58, 85 (1991).

[7] M.J. Dekkers, Geologie en Mijnbouw 76, 163 (1997).

[8] V. Skumryev, H.J. Blythe, J. Cullen, J.M.D. Coey, J. Magn. Magn. Mater. 196-197, 515 (1999).

[9] M. Bałanda, A. Wiecheć, Z. Kąkol, A. Kozłowski, D. Kim, J.M. Honig, Acta Phys. Pol. B 34, 1513 (2003).

[10] B. Handke, T. Ślęzak, M. Kubik, J. Korecki, J. Radioanal. Nucl. Chem. 246, 27 (2000).

[11] N.N. Greenwood, T.C. Gibb, Mössbauer Spectroscopy, Chapman and Hall, London 1971.

[12] M. Saporoschenko, C.C. Hinckley, G.V. Smith, H. Twardowska, R.H. Shileyf, R.A. Griffint, S.J. Russell, Fuel 59, 567 (1980).

[13] H. Stanjek, E. Murads, Clays Clay Miner. 42, 451 (1994).

[14] A. Bustamante, D. Lovera, R. Quille, A.V. Arias, J. Quiñones, Hyperfine Interact. 195, 63 (2010). 